\title{
IBUPROFEN: ORIGINAL VERSUS GREEN SYNTHESIS
}

\author{
Alina Crina MUREŞAN \\ "Dunarea de Jos" University of Galati, Faculty of Engineering \\ e-mail: alina.muresan@ugal.ro
}

\begin{abstract}
This paper makes a parallel between the original route versus the green route of Ibuprofen (non-steroidal anti-inflammatory drugs most commonly recommended) synthesis. The original route contained six steps with stoichiometric reagents (some reagents are very toxic: hydrochloric acid, ammonia), a lot of intermediate products, relatively low atom efficiency equal to $40.04 \%$ and substantial inorganic salt formation (aluminium trichloride hydrate). The green route of Ibuprofen synthesis developed only three steps, a lower amount of waste and by-products (only acetic acid that can be used for another applications) and an atom efficiency of $77.44 \%$. The green route for Ibuprofen synthesis is an exquisite example of a simple and elegant chemical/pharmaceutical manufacturing process and the nearly complete atom utilization of this streamlined process truly makes it a wasteminimizing, environmentally friendly technology.
\end{abstract} friendly

KEYWORDS: Ibuprofen, green synthesis, atom economy, environmentally

\section{Introduction}

The pharmaceutical industry is one of the most dynamic sectors of the chemical industry for this century. In a report conducted by the Centre for Responsive Politics, there were more than 1,100 lobbyists working in some capacity for the pharmaceutical business in 2017. In the first quarter of 2017, the health products and pharmaceutical industry spent 78 million dollars on lobbying member of the United States Congress [1].

The anti-inflammatory and analgesic drugs are a category of medicines which are produced every year in a very large amount. The most important medicines used as anti-inflammatory and analgesic are: Aspirin, Acetominophen (Paracetamol) and Ibuprofen. The last one is currently one of the most common overthe-counter medicine used as analgesic-antipyreticanti-inflammatory drugs for treating pain, fever and inflammation because Ibuprofen is probably the least toxic, being rarely associated with deaths from accidental or deliberate ingestion or with serious adverse reactions [2-5].

In 2011 the most commonly recommended NSAIDs (non-steroidal anti-inflammatory drugs) were: Aspirin (88 countries), Ibuprofen (90 countries), Diclofenac (74 countries), Indometacin (56 countries) and Naproxen (27 countries) [6].
Ibuprofen (Fig. 1) was discovered in 1955 in United Kingdom, in 1958 the compound code named BTS 8402 is given to a clinical trial (i.e. a trial on patients), in 1961 it was patented with the name 2-(4isobutylphenyl) propanoic acid, today called Ibuprofen.<smiles>CC(C)Cc1ccc(C(C)C(=O)O)cc1</smiles>
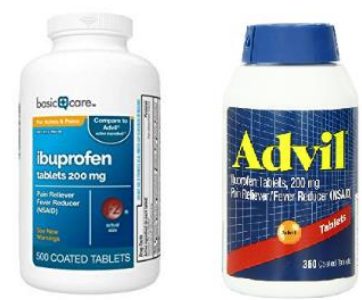

Fig. 1. Ibuprofen-NSAIDs drug with sales increased constantly in last decades

The compound was synthesized by pharmaceutical company Boots from United Kingdom, in 1969 clinical trials of Ibuprofen are launched in the United Kingdom on prescription only and from 1983 Ibuprofen was available without medical prescription. The medicine was recommended to be prescribed at up to $2.4 \mathrm{~g} /$ day (or higher dose in the USA) for the treatment of musculo- 
skeletal pain and inflammation as well as other painful conditions $[7,8]$.

Green chemistry is the practice of chemical science and manufacturing in a manner that is sustainable, safe, non-polluting and that consumes minimum amounts of materials and energy while producing little or no waste material.

Together with green chemical engineering, green chemistry must propose and modify or totally redesign chemical products such as: all materials involved in making a product should be incorporated into the final product, the use or generation of substances that pose hazards to humans and the environment should be avoided, the use of auxiliary substances should be minimized and preferably totally avoided, energy requirements should be minimized, products that must be dispersed into the environment should be designed to break down rapidly into innocuous product [9-13].

From the green chemistry point of view, the original synthesis of Ibuprofen generates a lot of dangerous waste and by-products, the energy was consumed with lower yield of the final product, so that it was necessary to improve or to modify the route of Ibuprofen synthesis.

\section{Ibuprofen synthesis}

\subsection{The original route for obtaining Ibuprofen}

The originally route, developed by the Boots Pure Drug Company-United Kingdom (the discoverers of Ibuprofen) contained six steps for Ibuprofen synthesis with stoichiometric reagents, relatively low atom efficiency and substantial inorganic salt formation (Fig. 2) [14].

It can be observed that the classical route uses from the first step aluminium chloride in a stoichiometric amount, which is then converted into aluminium trichloride hydrate waste. Another disadvantage for this method is the number of steps for obtaining the final product. So that, the six steps used for synthesis leads to auxiliary products that are not found in the final product, since the atom efficiency is lower.

Another negative result of this route that results from numbers of steps is energy efficiency. A lot of steps used for the final product synthesis imply a lot of energy quantities, so that the energy consumed is retrieved in the final price of the product. A lot of steps are used to obtain the final product involving a lot of catalytic reagents and intermediate products that are not reused at the final of steps.

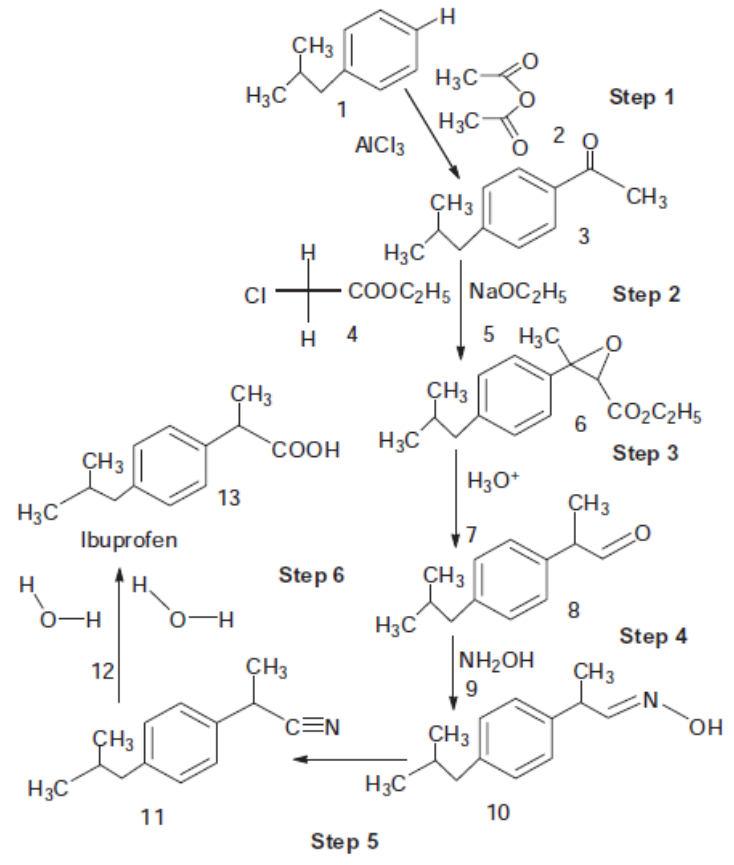

Fig. 2. The classical route for Ibuprofen synthesis used by Boots Company [14]

Atom economy or atom efficiency (A.E., \%) is an important parameter for green chemicals equations. In ideal reaction, the atom economy is $100 \%$, it means no waste, no by-products and that all reagents were used to obtain the final product.

The atom economy was calculated with equation [15]:

$$
\text { A.E. }(\%)=\frac{\text { mass of atoms in desired product }}{\text { mass of atoms in reactants }} \cdot 100
$$

In Table 1 were given the same parameters used to calculate the A.E. for each step of reactions for Ibuprofen synthesis under classical route (reagent chemical formula, relative molecular mass of reagents and relative molecular mass of used products).

From the data presented in Table 1 it could be observed that for the first step, the A.E. was 74.58\%, without calculating the mass of $\mathrm{AlCl}_{3}$ used as catalyst from Friedel-Crafts reaction that cannot be reused because this catalyst become waste after reaction.

The second step of reaction used three reactants and the atom economy was $71.49 \%$. It is important to mention that sodium ethoxide used as reagent was obtained in-situ from sodium hydroxide dissolves in excess of ethanol (solvent).

The green chemistry principles mention that auxiliary substances (e.g. solvents) should be made unnecessary wherever possible and innocuous when used [16]. More than that, sodium ethoxide is extremely flammable, harmful and corrosive (Dangerous Substances Directive 67/548/EEC). 
Table 1. The atom economy (\%) for classically route of Ibuprofen synthesis and parameters used to calculate him

\begin{tabular}{|c|c|c|c|c|c|}
\hline $\begin{array}{l}\text { Reactions } \\
\text { steps }\end{array}$ & $\begin{array}{l}\text { Reagents } \\
\text { chemical } \\
\text { formula }\end{array}$ & $\begin{array}{c}\text { Relative } \\
\text { molecular mass of } \\
\text { used reagents }\end{array}$ & $\begin{array}{c}\text { Relative } \\
\text { molecular mass of } \\
\text { used products }\end{array}$ & $\begin{array}{c}\text { Relative molecular } \\
\text { mass of by-products } \\
\text { or waste }\end{array}$ & $\begin{array}{c}\text { Atom } \\
\text { economy, } \\
\%\end{array}$ \\
\hline \multirow{2}{*}{ Step 1} & $\mathrm{C}_{10} \mathrm{H}_{14}$ & 134.0 & \multirow{2}{*}{176.0} & \multirow{2}{*}{60.0} & \multirow{2}{*}{74.58} \\
\hline & $\mathrm{C}_{4} \mathrm{H}_{6} \mathrm{O}_{3}$ & 102.0 & & & \\
\hline \multirow{3}{*}{ Step 2} & $\mathrm{C}_{12} \mathrm{H}_{16} \mathrm{O}$ & 176.0 & \multirow{3}{*}{366.5} & \multirow{3}{*}{104.5} & \multirow{3}{*}{71.49} \\
\hline & $\mathrm{C}_{4} \mathrm{H}_{7} \mathrm{O}_{2} \mathrm{Cl}$ & 122.5 & & & \\
\hline & $\mathrm{C}_{2} \mathrm{H}_{5} \mathrm{ONa}$ & 68.0 & & & \\
\hline \multirow{2}{*}{ Step 3} & $\mathrm{C}_{16} \mathrm{H}_{22} \mathrm{O}_{3}$ & 262.0 & \multirow{2}{*}{281.0} & \multirow{2}{*}{91.0} & \multirow{2}{*}{67.61} \\
\hline & $\mathrm{H}_{3} \mathrm{O}$ & 19.0 & & & \\
\hline \multirow{2}{*}{ Step 4} & $\mathrm{C}_{13} \mathrm{H}_{18} \mathrm{O}$ & 190.0 & \multirow{2}{*}{223.0} & \multirow{2}{*}{18.0} & \multirow{2}{*}{91.93} \\
\hline & $\mathrm{NH}_{3} \mathrm{O}$ & 33.0 & & & \\
\hline Step 5 & $\mathrm{C}_{13} \mathrm{H}_{19} \mathrm{NO}$ & 205.0 & 187.0 & 18.0 & 91.22 \\
\hline \multirow{2}{*}{ Step 6} & $\mathrm{C}_{13} \mathrm{H}_{17} \mathrm{~N}$ & 187.0 & \multirow{2}{*}{182.0} & \multirow{2}{*}{17.0} & \multirow{2}{*}{92.38} \\
\hline & $\mathrm{H}_{4} \mathrm{O}_{2}$ & 36.0 & & & \\
\hline
\end{tabular}

For the step free of the reactions for Ibuprofen synthesis using the classical route, the atom economy is lower than the first and second steps, with a value of $67.61 \%$.

It can be observed from Table 1 that the atom economy for the step four is higher, with a value of $91.93 \%$.

However, it is important to mention that the hydroxylamine used as reagent may explode on heating. Another negative aspect for this reagent is: hydroxylamine is an irritant to the respiratory tract, skin, eyes and other mucous membranes. It may be absorbed through the skin, it is harmful if swallowed and it is a possible mutagen. More than that, hydroxylamine is dangerous for the environment [17, 18].

On the step five of the classical method for Ibuprofen synthesis the intermediate product is a nitrile and the atom economy is $91.22 \%$.

The last step of the route obtaining for Ibuprofen was an atom economy of $92.38 \%$.

For the entire process it was observed that it was used only 206.0 relative molecular mass from the total relative molecular mass of reagent with a value of $514.5,308.5$ relative molecular mass was lost as waste or by-products.

If the analysis of the entire process for Ibuprofen synthesis using the classical route we can conclude some aspects: the process involved 6 steps, it was necessary 13 intermediate reagents for obtaining the final products, some reagents are very toxic, with a high negative impact on the environment, a lot of products were by-products or waste (hydrochloric acid, ammonia, acetic acid and aluminium trichloride hydrate).

Hydrochloric acid can cause skin burn, eye damage and irritation to different parts of our bodies (Dangerous Substances Directive 67/548/EEC).
Ammonia is not toxic for human body, but it is toxic for fish and amphibians and if waste is thrown into water, a ecological disaster will happened [19].

The six steps of Boots reaction for obtaining Ibuprofen needs a lot of energy consumption because most of the reactions require heating.

The last, but not the least disadvantage of the classical route for Ibuprofen synthesis is the atom economy of the entire steps with a value of $44.04 \%$, a very low value under green chemistry principles that generate a lot of waste.

\subsection{The green route for Ibuprofen synthesis}

In the 1980's was developed o new route for Ibuprofen synthesis, a green one with only three steps of reactions, involving a lower amount of waste and by-products, only seven intermediate reagents, most of them reused, and a higher atom efficiency than the classically route.

The green route was developed by the BootsHoechst-Celanese (BHC) Company (United States of America) (Fig. 3) and the process won the Kirpatrick Chemical Engineering Achievement Award in 1993 and the Presidential Green Chemistry Challenge Award in 1997 [20].

Table 2 presents same parameters used to calculate the atom efficiency for each step of reactions for Ibuprofen synthesis under green route (reagent chemical formula, relative molecular mass of reagents and relative molecular mass of used products).

It can be observed from Table 1 that from the first step of reactions with green route, the atom economy has the same value, $74.58 \%$ with the first 
step of reaction with classical route of Ibuprofen synthesis from isobutylbenzene and acetic anhydride.

But, the first step of reactions from green route is possible with hydrogen fluoride used as a catalyst and solvent for the reaction that can be recovered and reused repeatedly [21].<smiles>CC(=O)OC(C)=O</smiles>

Fig. 3. The green route for Ibuprofen synthesis used green process [20]
In BHC process the bath recycle times and capital expenditure are lesser when compared to Boots process. The result is increased economic benefits of company and non-polluted reagents. More than that, the hydrogen fluoride is the single solvent used for green Ibuprofen synthesis, simplifying product recovery and minimizing fugitive emissions.

If it is considered that the acetic acid obtained as by-product from the first step of the reaction is used for another applications, the atom economy for step one with green route is $100.00 \%$.

The second step of the green route is reduction of a ketone to an alcohol with an atom economy of $100.00 \%$. The catalyst used was Raney nickel (spongy nickel), a fine-grained solid composed mostly of nickel derived from a nickel-aluminium alloy with stability and high catalytic activity at room temperature [22].

The last step of reactions for Ibuprofen synthesis using the green route represents carbonylation of alcohol over a Pd as catalyst that can be recycled and reused [23]. The atom economy of the final step was $100.00 \%$.

For the entire process it was observed that was used 206.0 relative molecular mass from the total relative molecular mass of reagent with a value of 266.0 (only 60.0 relative molecular mass was lost under acetic acid form), so that the atom economy of the entire processes for Ibuprofen synthesis using green route was $77.44 \%$, almost double versus the value of the atom economy of the process using classical route.

Table 2. The atom economy (\%) for green route of Ibuprofen synthesis and parameters used to calculate him

\begin{tabular}{|c|c|c|c|c|c|}
\hline $\begin{array}{l}\text { Reactions } \\
\text { steps }\end{array}$ & $\begin{array}{c}\text { Reagents } \\
\text { chemical } \\
\text { formula } \\
\end{array}$ & $\begin{array}{c}\text { Relative } \\
\text { molecular mass of } \\
\text { used reagents } \\
\end{array}$ & $\begin{array}{c}\text { Relative } \\
\text { molecular mass of } \\
\text { used products } \\
\end{array}$ & $\begin{array}{c}\text { Relative molecular } \\
\text { mass of by-products } \\
\text { or waste }\end{array}$ & $\begin{array}{c}\text { Atom } \\
\text { economy, } \\
\% \\
\end{array}$ \\
\hline \multirow{2}{*}{ Step 1} & $\mathrm{C}_{10} \mathrm{H}_{14}$ & 134.0 & \multirow{2}{*}{176.0} & \multirow{2}{*}{60.0} & \multirow{2}{*}{74.58} \\
\hline & $\mathrm{C}_{4} \mathrm{H}_{6} \mathrm{O}_{3}$ & 102.0 & & & \\
\hline \multirow{2}{*}{ Step 2} & $\mathrm{C}_{12} \mathrm{H}_{16} \mathrm{O}$ & 176.0 & \multirow{2}{*}{178.0} & \multirow{2}{*}{0.0} & \multirow{2}{*}{100.00} \\
\hline & $\mathrm{H}_{2}$ & 2.0 & & & \\
\hline \multirow{2}{*}{ Step 3} & $\mathrm{C}_{12} \mathrm{H}_{18} \mathrm{O}$ & 178.0 & \multirow{2}{*}{206.0} & \multirow{2}{*}{0.0} & \multirow{2}{*}{100.00} \\
\hline & $\mathrm{CO}$ & 28.0 & & & \\
\hline
\end{tabular}

The green route for Ibuprofen synthesis is an exquisite example of how a simple and elegant chemical/pharmaceutical manufacturing route, initially a route with a lower atom economy can be made much cleaner, much favourable and much economical through implementation of green process technology.

If we consider that about $7.2 \cdot 10^{3}$ tons of Ibuprofen are produced each year [11] we can imagine how waste is not produced, a lot of energy is not consumed, and the process does not pollute the environment.

\section{Conclusions}

Observing Ibuprofen synthesis under the green chemistry principles it could be concluded that the original route was performed in six steps, with the productions a lot of by-products, a lot of waste, 
enormous quantities of energy consumed and serious damage of environment.

Synthesis of Ibuprofen under original route was an atom efficiency of only $40.04 \%$.

The green route, the Boots-Hoechst-Celanese process provides an elegant and efficient solution to a prevalent problem encountered in bulk pharmaceutical synthesis. The amount of waste is minimum (only three steps for reactions comparing with six steps in classical route), the catalyst and solvents are reused and recovered, the energy consumption is lower comparing with classically route.

The atom economy of entire processes for green synthesis of Ibuprofen is $77.44 \%$ and it lost only 60.0 relative molecular mass under acetic acid form. If this by-product is reused for another application, the atom economy becomes $100.00 \%$.

The nearly complete atom utilization of this streamlined process truly makes it a wasteminimizing, environmentally friendly technology.

\section{References}

[1]. Lipton E., Thomas K., Drug Lobbyists' Battle Cry Over Prices: Blame the Others, New York Times, 29.05.2017.

[2]. Davies N. M., Clinical pharmacokinetics of ibuprofen, the first 30 years, Clinical Pharmacokinetics, vol. 34, p. 101-154, 1998.

[3]. Oliveira I. O., Borges A., Borges F., Simoes M., Repurposing ibuprofen to control Staphylococcus aureus biofilms, European Journal of Medicinal Chemistry, vol. 166, p. 197-205, 2019.

[4]. Oliveira T. C. D., Lima J. F. D., Colaço M. V., Jesus L. T., Freire R. O., Marques L. F., Synthesis, characterization and spectroscopic studies of binuclear lanthanide complexes containing the anti-inflammatory drug Ibuprofen and $\mathrm{CH}_{3}$-disubstituted bipyridine ligands: Influence of methyl group position in the photoluminescence, Journal of Luminescence, vol. 194, p. 747-759, 2018.

[5]. Manrique-Moreno M., Heinbockel L., Suwalsky M., Garidel P., Brandenburg K., Biophysical study of the nonsteroidal anti-inflammatory drugs (NSAID) ibuprofen, naproxen and diclofenac with phosphatidylserine bilayer membranes, Biochimica et Biophysica Acta (BBA) - Biomembranes, vol. 1858, p. 2123-2131, 2016 .

[6]. McGettigan P., Henry D., Use of Non-Steroidal AntiInflammatory Drugs That Elevate Cardiovascular Risk: An Examination of Sales and Essential Medicines Lists in LowMiddle- and High-Income Countries, PLOS Medicine, vol. 10, e1001388, 2013.
[7]. Rainsford K. D., Ibuprofen: pharmacology, efficacy and safety, Inflammopharmacology, vol. 17, p. 275-342, 2009.

[8]. ***, https://pubchem.ncbi.nlm.nih.gov.

[9]. Lancaster M., Green Chemistry. An Introductory Text, Publisher the Royal Society of Chemistry Cambridge, U. K., ISBN 0-85404-620-8, 2002.

[10]. Thomas K. et al., Growing the Green Economy Through Green Chemistry and Design for the Environment A Resource Guide for States and Higher Education, A joint report by The Green Chemistry and Commerce Council Lowell Centre for Sustainable Production at the University of Massachusetts Lowell and The National Pollution Prevention Roundtable, Issued Publication Number 09-04-010, 2009.

[11]. Clark J., Macquarrie D., Handbook of Green Chemistry and Technology, Publisher Blackwell Science Ltd., ISBN 978-0-63205715-3, 2002

[12]. Dunn P. J., Wells A. S., Williams M. T., Green Chemistry in the Pharmaceutical Industry, Publisher Wiley-VCH Verlag GmbH \& Co., Print ISBN:9783527324187, 2010.

[13]. Manahan S. E., Green Chemistry and the Ten Commandments of Sustainability, $3^{\text {rd }}$ edition, Publisher: Chem Char Research Inc., 2010.

[14]. Doble M., Rollins K., Kumar A., Green Chemistry and Engineering, $1^{\text {st }}$ edition, Imprint Academic Press, eBook ISBN: 9780080524771, 2007.

[15]. Dicks A., Hent A., Green Chemistry Metrics: A Guide to Determining and Evaluating Process Greenness, Publisher: Springer, Springer Briefs in Green Chemistry for Sustainability, ISBN 3319105019, 2015.

[16]. Wardencki W., Curlo J., Namieoenik J., Green ChemistryCurrent and Future Issues, Polish Journal of Environmental Studies, vol. 14, p. 389-395, 2005.

[17]. Evelo C. T., Spooren A. A., Bisschops R. A., Baars L. G., Neis J. M., Two mechanisms for toxic effects of hydroxylamines in human erythrocytes: involvement of free radicals and risk of potentiation, Blood Cells, Molecules and Diseases, vol. 3, p. 280295, 1998.

[18]. Riemann H., On the Toxicity of Hydroxylamine, Acta pharmacologia, vol. 6, p. 285-292, 1950

[19]. Hecnar S. O., Acute and chronic toxicity of ammonium nitrate fertilizer to amphibians from southern Ontario, Environmental Toxicology and Chemistry, vol. 14, p. 2131-2137, 1995.

[20]. Cann M. C., Connelly M. E., The BHC Company Synthesis of Ibuprofen, a Greener Synthesis of Ibuprofen Which Creates Less Waste and Fewer Byproducts, chapter from "Real World Cases in Green Chemistry", p. 19-24, Publisher American Chemical Society, Washington DC, 2000.

[21]. Bond G. C., Webb G., Malonowski S., Marczewski M., Catalysis, Chapter 4: Catalysis by solid acids and bases, vol. 8, p. 107-156, Publisher Royal Society of Chemistry, Cambridge, UK, ISBN 978-0-85186-594-2, 1989.

[22]. Nishimura S., Handbook of Heterogeneous Catalytic Hydrogenation for Organic Synthesis, $1^{\text {st }}$ ed., Publisher New York: Wiley-Interscience, ISBN 978-0-471-39698-7, 2001.

[23]. Drahl C., Palladium's Hidden Talent, Chemical and Engineering News, vol. 86, p. 53-56, 2008. 